\title{
Neoliberalismo y actores políticos en la Argentina contemporánea
}

\author{
Juan Manuel Reynares*
}

Perfiles Latinoamericanos, 25(50)

2017 | pp. 279-299

DOI: $10.18504 / \mathrm{pl} 2550-013-2017$

\begin{abstract}
Resumen
En este artículo partimos de una lectura crítica de la literatura sobre actores políticos neoliberales en Argentina. Desde allí consideramos que la concentración de investigaciones en el nivel nacional, al interior de esa bibliografía, se relaciona con una definición de neoliberalismo como un conjunto de macropolíticas económicas estructurales. Frente a ello proponemos definir al neoliberalismo como una tecnología de gobierno que pretende volver hegemónica una lógica empresarial, entendiéndolo como un horizonte de sentido, conflictivo y contingentemente articulado. Ello da pie a una perspectiva de análisis de los procesos de identificación neoliberal en tanto heterogéneas trayectorias con distintos alcances espacio-temporales.
\end{abstract}

\begin{abstract}
In this paper we set out a critical reading of the literature on political neoliberal actors in Argentina. We consider that the concentration of these studies in the national level has to do with a definition of neoliberalism as a set of economical and structural macro politics. We propose to define neoliberalism as a technology of government that intends to hegemonize an "enterprise form" in different social spheres, articulating a symbolical framework in a contingent and contentious way. This insight allows analyzing neoliberal identification processes as heterogeneous trajectories with diverse geographic and temporal scopes.
\end{abstract}

Palabras clave: neoliberalismo, tecnología de gobierno, hegemonía, identificación política. Keywords: Neoliberalism, technology of government, hegemony, political identification.

* Doctor en Ciencia Política por el Centro de Estudios Avanzados de la Universidad Nacional de Córdoba. Becario posdoctoral del Consejo Nacional de Investigaciones Científicas y Técnicas (CONICET), con lugar de trabajo en el Instituto Académico-Pedagógico de Ciencias Sociales, Universidad Nacional de Villa María | juanmreynares@gmail.com 


\section{Introducción}

E

neoliberalismo en la Argentina ha ocupado un lugar central en las ciencias sociales de este país en el último cuarto de siglo, lo que incluyó, entre otras líneas de investigación, el análisis de los actores políticos involucrados en la implementación de las políticas públicas económicas que tradicionalmente se han considerado como el núcleo del neoliberalismo — reforma estatal, desregulación económica y ajuste fiscal—. Esto generó una mayor presencia de estudios sobre el menemismo, la Alianza y las asociaciones académicas y empresariales — como la Fundación Mediterránea y la Fundación de Investigaciones Económicas Latinoamericanas (FIEL) - , mientras que se han dejado en lugares relativamente marginales los interrogantes sobre otros actores políticos neoliberales que se ubiquen por fuera del ámbito de injerencia del Estado nacional.

En este marco analítico, consideramos que es posible trazar un vínculo entre la caracterización del neoliberalismo que se construye en cada caso de estudio, y el tipo de preguntas de investigación que pueden formularse allí. A partir de esa hipótesis, en este artículo pretendemos delinear las principales características con que definen al neoliberalismo aquellos estudios que se concentran en la experiencia menemista, o más en general, en los actores políticos detrás de la implementación de estas medidas de ajuste, reforma y desregulación a nivel nacional. A partir de allí, desplazando el eje de esa mirada, nos proponemos plantear una redescripción del neoliberalismo más allá, o más acá, de esas medidas puntuales, y notar los efectos que tal supone para indagar los procesos de constitución de actores políticos neoliberales por fuera del sistema político-institucional argentino a nivel nacional, e incluso en ámbitos no considerados tradicionalmente como "políticos".

En función de ese objetivo, en este trabajo consideraremos críticamente algunas de las perspectivas analíticas más extendidas sobre el neoliberalismo, para subrayar que, si bien divergen en sus presupuestos ontológicos y epistemológicos, comparten una misma caracterización de este fenómeno, centrada en un conjunto coherente y coordinado de políticas económicas implementadas a nivel nacional. Ante eso, sostendremos una definición relativamente novedosa del neoliberalismo a la vez, como un discurso político — para lo cual utilizaremos algunas definiciones de la teoría política del discurso (TPD) - y como una tecnología de gobierno, profundizando aquí en algunos planteos de M. Foucault sobre la racionalidad neoliberal de gobierno. La articulación de estos lenguajes en una caracterización compleja del neoliberalismo — que no se agote en el estudio de los casos nacionales - permite expandir la investigación sobre la pervivencia del neoliberalismo, en tanto fenómeno característico de nuestro tiempo, a diversos actores políticos de variado alcance geográfico y temporal. 


\section{Neoliberalismo y actores políticos: la centralidad del Estado nacional}

La interpretación más extendida sobre el neoliberalismo que subyace a las investigaciones sobre la emergencia, consolidación y debilitamiento de actores políticos neoliberales en la Argentina, lo resume en un conjunto de políticas económicas a nivel del Estado nacional. Ello es parte de una lectura más general, utilizada en diversos estudios surgidos dentro de las ciencias sociales europea y estadounidense desde la década de 1970, que lo define como un conjunto de reformas en países centrales y periféricos, que apuntaban a reducir la presencia directa del Estado en los procesos económicos, liberando las economías nacionales al libre juego del mercado mundial, a partir de una lectura de ciertos problemas considerados típicos de una economía: la estabilidad de los precios, en un lugar preponderante, y en menor medida, el empleo y el ahorro. ${ }^{1}$ Esto implicaba un cambio en la composición del aparato estatal mediante una contracción del gasto público, la venta de activos estatales al sector privado y la descentralización de la estructura administrativa hacia unidades más pequeñas.

El principal fundamento de esa interpretación residió en un conjunto de teorías económicas desarrolladas a mediados del siglo xx por intelectuales de la Escuela de Viena, el ordoliberalismo alemán y el neoliberalismo norteamericano. Estos retomaron elementos del liberalismo clásico para desarrollar una fuerte crítica a las economías centralizadas, desde aquellas bajo la égida del "socialismo real" hasta las experiencias bienestaristas de posguerra. Estos ataques se enfocaban en la necesidad de estabilidad monetaria, por lo que la inflación se convertía en uno de los principales obstáculos a superar. La contrapartida al exceso de intervencionismo estatal era la generación de una estructura de incentivos para aumentar la productividad de los agentes económicos, a través de la reducción de impuestos sobre las ganancias más altas, y la flexibilización laboral que permitiese una mayor tasa de rentabilidad a los empresarios, así como asegurar la mayor eficiencia en el proceso productivo. De este modo, el mercado era promovido artificialmente para hacer funcionar una dinámica competitiva que redundara en una distribución de recursos estable.

De este modo, las reformas, según esta visión canónica, eran presentadas por sus portavoces como el resultado de dictados técnicos con una pretendida neutralidad ideológica (Morresi, 2008; Reynares, 2012b). Esta postura económica

1 A mediados de la década de 1970, una situación económica conflictiva en los países centrales produjo circunstancias favorables para que el ideario neoliberal comenzara a calar en las dirigencias políticas de los países centrales, por ejemplo, con los gobiernos "neoconservadores" de Thatcher en Gran Bretańa y Reagan en Estados Unidos. Al mismo tiempo, esta agenda comenzaba a ser implementada en América Latina a través de gobiernos impuestos por golpes y dictaduras cívico-militares con amplio apoyo de sectores del empresariado local y transnacional. 
planteaba la necesidad de "un Estado fuerte en su capacidad de quebrar el poder de los sindicatos y en el control del dinero, pero limitado en lo referido a los gastos sociales y a las intervenciones económicas" (Anderson, 2003: p. 2), lo que incluía la privatización de las empresas públicas que generaban déficit y no eran administradas con eficiencia. Durante la década de los noventa, este conjunto de medidas económicas estructurales fue conocido como el "Consenso de Washington". ${ }^{2}$

A partir de esta caracterización centrada en la economía y la figura del Estado, los estudios sobre la constitución de actores políticos neoliberales han lidiado con un problema de investigación complejo: la expansión de esta "agenda” neoliberal en sectores cada vez más amplios de los electorados nacionales. Anderson, por ejemplo, consideraba que:

En los países del capitalismo avanzado, el neoliberalismo había tenido su origen a partir de una crítica implacable a los regímenes socialdemócratas. Sin embargo, y con excepción de Suecia y Austria, hacia fines de los años 80, la propia socialdemocracia europea fue incorporando a su programa las ideas e iniciativas que defendían e impulsaban los gobiernos neoliberales. Paradojalmente, eran ahora los socialdemócratas quienes se mostraban decididos a llevar a la práctica las propuestas más audaces formuladas por el neoliberalismo (Anderson, 2003: p. 14. Cursivas agregadas).

De este modo, el neoliberalismo como una serie más o menos ordenada de políticas en torno a la reproducción de mercados mediante reformas estatales se propagaba por todos los países aun de forma aparentemente contradictoria en los casos en que los propios partidos gobernantes habían sido defensores de una activa participación estatal en clave bienestarista unos pocos años atrás. En el caso argentino, los problemas de esta caracterización del neoliberalismo han sido similares para comprender a los actores políticos que lo implementa-

2 Puntualmente, en el caso argentino, la asunción del gobierno justicialista de Menem en julio de 1989 señaló el inicio de la implementación de una batería reformista pro mercado, inaugurada con la Ley de Emergencia Económica, $N^{\circ} 23.696$, y la Ley de Reforma del Estado, $\mathrm{N}^{\circ} 23.697$, en septiembre de ese mismo año. La base de todo este proceso de reforma y estabilización fue fijada en su generalidad por el Consenso de Washington, un "decálogo instrumental para superar el modelo 'estatista" (Gambina, 2001) que implicaba: reducción del déficit fiscal a no más de $2 \%$ del PBi; disminución del gasto público mediante la eliminación de políticas sociales universalistas; expansión de la recaudación impositiva ampliando y generalizando la base imponible; tasas de interés positivas para atraer capitales; tipo de cambio alto y estable; eliminación de barreras arancelarias facilitando así la apertura comercial; promoción de las inversiones externas atractivas; favorecimiento de "la estrategia de acumulación en la iniciativa privada"; desregulación del mercado de trabajo y en general de toda la economía, y aseguramiento de los derechos de propiedad promoviendo reformas institucionales necesarias. 
ron bajo la pervivencia institucional de la democracia. En ese sentido, el "giro" que el peronismo nacional, bajo el liderazgo de Carlos Menem, dio apenas iniciado su mandato, sobreactuando incluso el cambio de orientación económica de su mensaje de campańa — que había estado centrado en tópicos del discurso peronista de reactivación económica vía la intervención directa del Estado, y el llamado a un acuerdo sectorial entre empresarios y trabajadores-, fue objeto de múltiples investigaciones (Barros, 2002; Borón et al., 1995; Levitsky, 2005). Así, Borón sostenía que lo sorprendente del caso era que Menem había podido poner en práctica un "ajuste estructural [...] extremadamente duro sin precipitar conflictos sociales y políticos inmanejables [...] y sin que, al menos hasta ahora, se pusiera en cuestión la estabilidad institucional” (Borón, 1995: p. 17).

La expansión política del neoliberalismo, a pesar de sus efectos negativos en la población, en actores políticos tradicionalmente extraños a las demandas dominantes aparece entonces, para esta perspectiva, como un fenómeno aparentemente paradojal y sorprendente. Frente a ello, surgieron diversas respuestas a las que es posible ordenar en dos conjuntos, cuyo criterio de clasificación parte de ciertas presunciones ontológicas y epistemológicas a través de las cuales se ha intentado comprender las dinámicas de consolidación del neoliberalismo en una serie cada vez más extendida de actores políticos.

Por un lado, una respuesta posible considera que la consolidación del neoliberalismo en la sociedad se produjo merced a la adaptación pragmática de las dirigencias partidarias nacionales a un proceso económico estructural de apertura, desregulación económica y ajuste fiscal. El neoliberalismo era comprendido como una agenda de políticas económicas que reflejaba cambios estructurales a nivel mundial y que se había configurado a partir de la difusión de las ideas de grupos de economistas y la presión corporativa de grandes grupos empresariales y financieros. La victoria de partidos de derecha en algunos países centrales, como Estados Unidos o Inglaterra, había abierto la puerta a la implementación de estas medidas, que asumió características particulares según el país.

En la Argentina, la pregunta a por qué el electorado peronista seguía apoyando una propuesta que iba en contra de sus intereses sectoriales estructuró gran parte del debate de las ciencias sociales durante los noventa. Levitsky encontró las principales razones de este fenómeno en la organización e institucionalidad del peronismo, ya que "la estructura descentralizada del PJ probablemente ayudó al partido a mantener su base militante en los años noventa [ya que en esa red descentralizada y desorganizada se mantuvieron] canales para la expresión de sus creencias peronistas" (Levitsky, 2001: p. 53). Esto era válido tanto para militantes poco numerosos pero fuertemente identificados con el imaginario peronista como para un grupo más grande de militantes, que aun disconforme 
con el giro neoliberal, no se vieron obligados a enfrentar la decisión entre volverse neoliberales o dejar el partido.

La tesis de Levitsky, enfatizando la organización específica del peronismo en términos partidarios, pretende contribuir a la explicación de la estabilidad y apoyo de las bases partidarias peronista al gobierno de Menen en diversos momentos de su administración. De esta manera, la respuesta de Levitsky se enfocó específicamente en la organización partidaria, reduciendo la complejidad de las dinámicas ideológicas a dos posturas aparentemente excluyentes: o bien se estaba conforme con "el giro neoliberal" que se identificaba de modo unívoco con el menemismo a nivel nacional, o bien se practicaba "el peronismo tradicional a nivel popular". En cualquier caso, en la mirada de Levitsky, tanto las conductas de los dirigentes peronistas que se adherían a un diagnóstico y una batería de medidas neoliberales, como las de los militantes y punteros que incluso rechazaban dicha transformación cupular, respondían a un cálculo puesto en juego para garantizar la supervivencia de sus respectivas posiciones de poder. ${ }^{3}$

Por otro lado, una amplia gama de análisis ha discutido la mera racionalidad instrumental de las élites y los miembros de los partidos, y su organización, como factores explicativos de la expansión neoliberal. Dichos estudios cuestionan la caracterización del neoliberalismo como el resultado de transformaciones estructurales que se reflejan —en mayor o menor medida pero siempre a posteriori- en el ámbito político. En este sentido, se ha hecho hincapié en la constitución de los actores que posibilitaron la aceptación de las medidas neoliberales por amplios sectores de la población, mediante una serie de procesos discursivos con los que ciertas interpretaciones sobre el Estado, el mercado o la democracia, entre otros significantes, se volvieron hegemónicas. Por tal causa, estos análisis se han detenido en las articulaciones discursivas que se suscitaron en cada caso nacional y que permitieron la introducción, legitimada por los procesos electorales y por el apoyo masivo, de un conjunto de medidas neoliberales que resultaban perjudiciales para vastos sectores de la población. De este modo, han sido capaces de analizar el carácter conflictivo e histórico de las transformaciones conocidas como neoliberales, bajo gobiernos de distinto signo partidario y con diversas trayectorias identitarias (Hall, 1988; Larner, 2000).

3 Lo cual se traslada, mutatis mutandis, a los estudios sobre las dirigencias provinciales del peronismo durante los noventa, que planteaban la adaptación de estas cúpulas a lo establecido por el liderazgo nacional bajo la premisa de conservar o acrecentar la influencia sobre sus bastiones locales. Véase, por ejemplo, Closa (2010). 
En Argentina, los estudios que dan lugar a la dimensión discursiva en la investigación sobre el neoliberalismo se han detenido en las dinámicas de construcción, consolidación y debilitamiento del menemismo (Aboy Carlés, 2001; Barros, 2002; Canelo, 2001; Muñoz, 2010; Portantiero, 1995; Pucciarelli, 2011; Sidicaro, 1995), como también en los vínculos entre agrupaciones empresariales y académicas defensoras de la desregulación económica y la recomposición del gasto fiscal (Camou, 1998; Morresi, 2008; Beltrán, 2008), o bien la composición y el proyecto de la Alianza que gobernó el país entre 1999 y 2001 (Pucciarelli \& Castellani, 2014). Con todas sus diferencias, los estudios que utilizan esta perspectiva complejizan al fenómeno neoliberal multiplicando sus dimensiones de análisis y actores involucrados.

Deteniéndonos en los que se sostienen sobre un horizonte onto-epistémico específicamente discursivo, existen diversos análisis que comprenden el relato menemista, en tanto expresión a nivel nacional del neoliberalismo, como un discurso centrado en la estabilidad (Barros, 2002), o bien, como una identidad política que neutraliza las diferencias sociales a partir del énfasis en la dimensión de orden nacional-estatal antes que en la de ruptura nacional-popular (Aboy Carlés, 2001). En estos casos no hay una alusión ni una problematización explícitas del neoliberalismo, pero sí del actor político que dio forma y justificó las reformas y políticas públicas reconocidas como neoliberales a nivel nacional. Estos estudios parten de una asunción ontológica político-discursiva de lo social, que impide pensar los procesos políticos como epifenómenos de dinámicas subyacentes, estructurales. Precisamente, el presupuesto de la constitución discursiva de lo social habilita un análisis relacional del actor político, por lo que se estudia el proceso de su constitución mediante la articulación de una serie de demandas, antes de presuponer su entidad o sus intereses como expresión lineal y unívoca de su ubicación en la estructura económica o social (Laclau \& Mouffe, 2005).

Estos análisis que asumen al neoliberalismo como un discurso - y por lo tanto como un proceso dinámico, conflictivo y contingente- han avanzado significativamente al apuntar los elementos simbólicos que se han puesto en juego para la configuración del discurso hegemónico neoliberal, aunque siempre ubicándose en el escenario nacional. Así, las políticas económicas nacionales precisaron de una mediación discursiva constitutiva, cuya dinámica se concentra en los actores partidarios de nivel federal. Estos análisis han complejizado los estudios sobre la hegemonía neoliberal —su emergencia, consolidación y debilitamiento- al considerar las dinámicas discursivas que hacen posible su constitución como una ideología, como un orden, un lenguaje o un imaginario con arraigados efectos sociales. Sin embargo, al no proveer una definición positiva del neoliberalismo más allá de las caracterizaciones canónicas 
que acabamos de revisar, han concentrado el alcance de su interrogación al nivel nacional.

Esta excesiva centralidad en el Estado nacional, y sobre todo en las políticas económicas a ese nivel, ha dejado poco lugar a la problematización de otros procesos de identificación política por fuera de ese ámbito. Allí se ubican, por ejemplo, los análisis sobre las trayectorias identitarias de las dirigencias partidarias provinciales desde los ochenta en Argentina (Reynares, 2012a, 2014; Erbetta, 2011; Manzo, 2011). Así, el análisis enfocado en el espacio nacional corre el riesgo de conllevar simplificaciones que no comprendan las continuidades y modulaciones neoliberales que persisten en nuestro sistema político en el nivel subnacional, o incluso en "las subjetividades y las tácticas de la vida cotidiana" (Gago, 2014: p. 10) más allá de los términos macroeconómicos y macropolíticos.

\section{Más allá (y más acá) del Estado nacional: "forma empresa" y discurso neoliberal}

De lo que se trata entonces es de indagar en otras definiciones del neoliberalismo que desplacen al Estado nacional — pensado como una institución unitaria que se expresa en las políticas públicas- del centro de su definición. Por esta vía se podría indagar, en el caso argentino, en las dinámicas de constitución identitaria en que se encarna el neoliberalismo más allá, o más acá, de la experiencia menemista. Es así que se vuelve necesario lidiar con una caracterización del neoliberalismo que lo delimite nítidamente, pero sin agotar su sentido en una política pública o una corriente partidaria interna siempre a nivel del Estado nacional.

En ese sentido, una caracterización diferente del neoliberalismo es la que se desprende del trabajo de Michel Foucault de los años setenta. Allí se plantea al neoliberalismo como una tecnología de gobierno o, más en general, en una racionalidad de gobierno basada en una "forma-empresa", cuyos efectos de individuación se expanden a todos los ámbitos sociales (Foucault, 2007). Así se desarma al Estado de su pretendida universalidad para observarlo como otro campo de disputa en el que se despliegan diversas lógicas de sujeción/subjetivación. En este marco de ideas, el enfoque discursivo que se nutre de la obra de Laclau, y que se concentra en el estudio de la emergencia, consolidación y debilitamiento de las lógicas sociales antes que en el de entidades plenamente delimitadas (Laclau, 2004), también sirve para rastrear al neoliberalismo como un discurso politico, es decir, como un precipitado de articulaciones contingentes y conflictivas que atraviesan actores, organizaciones o instituciones, y que toma forma a través de una retotalización metafórica en torno a una lógica so- 
cial empresarial que sobredetermina progresivamente a un número mayor de demandas y prácticas sociales. ${ }^{4}$

De este modo, en la intersección de estos dos enfoques —esto es, en la definición del neoliberalismo como un discurso político que promueve una tecnología de gobierno centrada en la expansión de cierta "forma empresa" en todos los ámbitos de interacción social- evitamos caracterizar al neoliberalismo desde la centralidad del Estado nacional, ampliando así el rango de preguntas a realizar sobre sus efectos políticos. Esto permite problematizar, entre otros posibles objetos, los procesos de identificación política en actores partidarios provinciales bajo este discurso, lo que abre un panorama analítico más amplio que pueda dar cuenta de las continuidades y rupturas del neoliberalismo en la historia política argentina contemporánea. Esto se vuelve posible en tanto la singularidad del neoliberalismo no radica necesariamente en las políticas públicas de desregulación y ajuste como algún tipo de núcleo esencial. Dicha especificidad no se encuentra solo en medidas puntuales, sino en cierta lógica de organización de la actividad de gobierno que no está limitada a la jurisdicción nacional o al nivel económico de la política pública. Esta lógica se expande y consolida de manera conflictiva, sostenemos, mediante una dinámica discursiva de desplazamientos y retotalizaciones hegemónicas que están en la base de los procesos de identificación política. Hacia una profundización de esta doble caracterización del neoliberalismo - como tecnología de gobierno, a la vez que como discurso político- nos abocamos ahora.

\section{La gubernamentalidad neoliberal}

Una caracterización del neoliberalismo que dé pauta para estudiar los procesos de identificación política a nivel subnacional adquiere sentido si cuestionamos la misma noción de estatalidad que sustenta la definición canónica expuesta en el apartado anterior. Ello no supone rechazar al Estado como objeto de análisis — y disputa —, sino discutir su pretendida unidad y coherencia, y el modo en que se actualiza históricamente. Precisamente, Foucault partió de discutir la necesidad de la ligazón del gobierno a la instancia estatal, al definirlo sucintamente como la conducción de conductas, pudiendo ser así el gobierno de los niños, del Estado y del hogar, mediante la intervención regulada sobre el campo de acciones presentes y futuras de los individuos (Castro Gómez, 2010).

4 Es conocido el uso que la TPD hace de la noción de "discurso" foucaultiana, por lo que no ahondaremos en el tema. Hacemos explícito que, tal como Laclau y Mouffe han sostenido, la acepción ontológica de discurso incluye prácticas lingüísticas y no lingüísticas. Véase Laclau \& Mouffe (2005: pp. 142-155). 
El Estado pierde cualquier idea de autonomía institucional, se desfonda, se vuelve el objeto de una superficie de tensiones y conflictos que imposibilitan cualquier pretensión de universalidad. De este modo, Foucault sostenía que

[...] el Estado no tiene esencia. El Estado no es un universal, no es en sí mismo una fuente autónoma de poder. El Estado no es otra cosa que el efecto, el perfil, el recorte móvil de una perpetua estatización o perpetuas estatizaciones, de transacciones incesantes que modifican, desplazan [...] las fuentes de financiamiento, las modalidades de inversión, los centros de decisión, las formas y los tipos de control, las relaciones entre poderes locales, autoridad central, etc. [...] el Estado no es nada más que un régimen de gubernamentalidades múltiples (Foucault, 2007: p. 96. Cursivas agregadas).

Así, al desplazar al Estado en tanto entidad unitaria para hacer foco en el gobierno, la noción de gubernamentalidad se vuelve central en el argumento foucaultiano. ${ }^{5} \mathrm{La}$ "gubernamentalidad" como tal es tematizada en diversas ocasiones tanto por Foucault $(2006,2007)$, como por muchos de los que han estudiado su obra o han desarrollado programas de investigación bajo su influencia teórica (Lemke, 2006; Rose, 2012; Rose, O’Malley \& Valverde, 2014; Castro Gómez, 2010 $)^{6}$ y tiene varios significados. En singular será utilizada por Foucault para referirse al

conjunto constituido por las instituciones, los procedimientos, análisis y reflexiones, los cálculos y las tácticas que permiten ejercer esa forma bien específica, aunque muy compleja, de poder que tiene por blanco principal la población, por forma

5 La gubernamentalidad ha sido profusamente analizada desde su puesta en juego por Foucault a mediados de los setenta. En este artículo haremos uso de esta noción —y del juego de palabras a ella asociada, como racionalidad de las prácticas y tecnología de gobierno - para dar al neoliberalismo una densidad analítica que los estudios que lo definen como un conjunto coherente y coordinado de políticas públicas a nivel nacional generalmente no poseen. No es la intención indagar en la distinción categorial entre prácticas, tecnologías, racionalidades, dispositivos, o discutir sobre la ubicación del estudio de las gubernamentalidades al interior de la obra foucaultiana. Proponemos más bien la posibilidad de construir algunas superficies de articulación entre la noción de gubernamentalidad, como racionalidad que ordena las prácticas sociales en tanto una gramática, y la noción de discurso, este último en un sentido ontológico que trascienda la distinción tradicional entre un registro lingüístico y otro no lingüístico. En esta dirección, las dinámicas de desplazamiento metonímico y de retotalización metafórica que subyacen a los procesos de identificación política (Laclau, 2014) en el marco de la teoría política de discurso, proveen una mirada novedosa sobre la expansión (o retracción) de la racionalidad de gobierno neoliberal.

6 La literatura especializada sobre la noción de gubernamentalidad, y más en general sobre la obra de Foucault es vastísima, y no pretendemos aquí agotar las referencias a ella. 
mayor de saber la economía política y por instrumento técnico esencial los dispositivos de seguridad (Foucault, 2006: p. 136). ${ }^{7}$

La gubernamentalidad vendría a señalar un modo de comprender y analizar el ejercicio del poder sobre la población mediante los conocimientos de la economía política a través de dispositivos de seguridad. Dicho ejercicio reconoce distintas modalidades cuya dinámica delimita los contornos de esa realidad producida que es el Estado, esto es, distintas gubernamentalidades que atraviesan el Estado como un campo de disputa. Se vuelve así posible una genealogía del Estado que no se interrogue por él en tanto una realidad ya dada de forma plena. Escribe Castro Gómez:

En lugar de ver al Estado como un objeto real del cual se deducen determinadas prácticas políticas, el camino genealógico es justamente el contrario: examinar primero la emergencia histórica de diferentes racionalidades de gobierno (el poder pastoral, la razón de Estado, el liberalismo, el neoliberalismo) para luego, a partir de ellas, analizar el modo en que se ha constituido el Estado (Castro Gómez, 2010: p. 176).

El neoliberalismo se comprende entonces como una racionalidad de gobierno que funge como una gramática que ordena las prácticas con las cuales se regula las acciones de los individuos, promoviendo así condiciones de aceptabilidad en situaciones de inequidad para gobernantes y gobernados (Castro Gómez, 2010). En ese marco, para Foucault la gubernamentalidad neoliberal se recorta históricamente de otra tecnología de gobierno que había incidido en la constitución de un área legítima de acción estatal, el liberalismo. Este asume como presupuesto la natural libertad del hombre en cuanto tal, en su capacidad de buscar la felicidad sin dañar la libertad de los otros por cualquier medio posible. Habría de esta forma una dimensión natural en el hombre, propia, que pugna por su bienestar. Esa dimensión económica no debe ser entonces influenciada por el Estado, ya que le estaría diciendo al hombre cómo ser feliz, una tendencia que ya está naturalmente en cada hombre (Kant, 2010). Esa esfera económica propia del individuo no se considera en el neoliberalismo, según el análisis foucaultiano, ya que, en este caso, "no se trata simplemente de liberar la economía. Se trata de saber hasta dónde podrán extenderse los poderes políticos y sociales de información de la economía de mercado" (Foucault, 2007: p. 150).

7 Inmediatamente Foucault menciona otros dos significados de la gubernamentalidad, y en distintas partes de su obra desliza otras de sus acepciones que poseen en general cierto parecido de familia. Véase O’Malley \& Valverde (2014). 
El mercado en su acepción liberal, como esfera de intercambio de sujetos naturalmente inclinados a la felicidad, debe ser liberado a su propia dinámica, por lo que el Estado solo debe dedicarse a garantizar la seguridad de esos hombres libres. El neoliberalismo, por su parte, implicará la intervención activa y artificial para trasladar la idea regulativa del mercado a todos los ámbitos, incluso el estatal, sin asumir una natural tendencia a la búsqueda utilitaria de bienestar por parte de los hombres. Para ponerlo en palabras del propio Foucault, el arte de gobierno neoliberal supone que "[...] no va a existir el juego del mercado al que debe dejarse libre y el ámbito donde el Estado comience a intervenir, pues justamente el mercado, o, mejor, la competencia pura, que es la esencia misma del mercado, sólo puede aparecer si es producida, y si es producida por una gubernamentalidad activa (Foucault, 2007: p. 154. Cursivas agregadas).

El mercado entonces no debe impermeabilizarse debido a las características naturales de su accionar, "no se trata de liberar un lugar vacío sino de remitir, referir, proyectar en un arte general de gobernar los principios formales de una economía de mercado" (Foucault, 2007: p. 157. Cursivas agregadas). En suma, el mercado, reducido al elemento competitivo en su interior, no posee un referente empírico que agote su dinámica sino que es pensado como una forma. Esta "forma mercado" pasa de ser un principio de limitación del gobierno y el alcance del Estado — como lo era bajo la gubernamentalidad liberal—, a ser su principio de regulación y organización; y más en general pretende serlo de cualquier espacio de interacción humana.

El neoliberalismo ofrece como punto de contraposición al liberalismo el modo en que se asume al individuo. En la prédica liberal, el Estado debe limitarse a asegurar el funcionamiento natural del mercado, donde el hombre expresa sus más variadas intenciones con el fin del bienestar volviéndose un sujeto de intercambio. Por su parte, la escuela neoliberal en el análisis foucaultiano propone "la producción activa del homo oeconomicus como sujeto de competencia que funciona como la condición no natural para el pleno desarrollo del juego también artificial del mercado" (Rossi \& Blengino, 2011: p. 34). El individuo neoliberal es producido mediante una específica tecnología de gobierno para competir de forma aparentemente libre en espacios diversos bajo la lógica expandida del mercado. La intervención neoliberal no alude solo a la economía, sino que se expande a todos los ámbitos de la vida humana, siempre en pos de asegurarse activamente el buen funcionamiento - no natural, sino precisamente artificial — de una economía de mercado. ${ }^{8}$ El homo oeconomicus se construye

8 El trabajo de Gago (2014) avanza radicalmente en la indagación de la potencialidad analítica del neoliberalismo como gubernamentalidad para observarlo "desde arriba" y "desde abajo". Escribe Gago:

"Foucault ha dicho que la innovación radical del neoliberalismo es que se trata de una forma de gober- 
en este contexto como "empresario de sí mismo, que es su propio capital, su propio productor y la fuente de sus ingresos" (Foucault, 2007: p. 265). Al tiempo que el individuo se comprende como empresario de sí mismo, es también moralmente responsable de su destino, exitoso o frustrado. Estas dos características traen aparejada una aceptación de la realidad como precondición para la adaptación necesaria a fin de lograr el éxito.

La aceptación y adaptación de la realidad, la responsabilidad individual y la asunción empresarial de cada sujeto son, para Foucault, las marcas del individuo en su aspecto de homo oeconomicus en el neoliberalismo. A partir de estas rápidas anotaciones, el neoliberalismo se distingue como una tecnología de gobierno en la que la relación entre Estado y mercado asume un contorno que se reproduce, desplazándose, en distintas esferas de regulación de la vida. En otras palabras, "[...] el neoliberalismo [...] se apoya en una concepción en la que el Estado mínimo tiene como correlato una gubernamentalidad máxima que se ve reflejada como un dispositivo ambiental de producción de una subjetividad y una antropología del homo oeconomicus estructurado desde el lugar de la competencia que, por otro lado, asume una dimensión trascendental [...]" (Rossi \& Blengino, 2011: p. 43).

Esta trascendentalidad de la competencia se refiere al carácter formal que asume el mercado en la expansión de su lógica a cualquier espacio social. ${ }^{9}$ Es por eso que ni el mercado ni la competencia o la empresa aluden a un conjunto positivamente delimitado de entidades, significantes o individuos, sino a cierta gramática que reordena constitutivamente cualquier práctica y le confiere un sentido parcialmente novedoso. Dicha lógica configura una regularidad en la

nar por medio del impulso a las libertades. Lo que a primera vez parece una contradicción, se vuelve una forma sofisticada, novedosa y compleja de enhebrar, de manera a la vez íntima e institucional, una serie de tecnologías, procedimientos y afectos que impulsan la iniciativa libre, la autoempresarialidad [...]" (Gago, 2014: p. 10). La autora apunta a “[...] pensar la gubernamentalidad en términos de ampliación de libertades y por tanto analizar el tipo de ensamblaje productivo y multiescalar que implica al neoliberalismo actual como modo de gobierno y de producción de realidad que también desborda ese gobierno" (Gago, 2014: p. 16).

9 Al estudiar la gubernamentalidad neoliberal, Foucault se enfocó en economistas de la escuela de Friburgo: Eucken, Böhm, Muller-Armack, entre otros, que participaron activamente del gobierno de L. Erhard en la Alemania de posguerra, y a la escuela norteamericana cuyo centro eran Chicago y Columbia y economistas como Simmons, Becker y Schulz. Foucault analizó sus obras e intervenciones políticas y rastreó cómo en ellas se propone una racionalidad económica que se pretende capaz, en el caso alemán, de refundar la legitimidad estatal a partir de la idea de libertad económica. El caso norteamericano es fecundo para el análisis de la expansión de la economía a todas las formas de comportamiento como en los casos del "capital humano" o de la política penal (Foucault, 2007: pp. 93-305). Esta redefinición del neoliberalismo, en torno a la proyección de la forma de una economía de mercado a diversos ámbitos sociales, permite el estudio de su expansión o retracción sin limitarse a las políticas de desregulación y apertura económica de alcance nacional que, como hemos visto arriba, tienden a ser tratadas como indicadores exclusivos de neoliberalismo. 
dispersión de prácticas sociales, bajo el principio de competencia de mercado. ${ }^{10}$ Así, escribe Castro Gómez, "[...] se trata, pues, de una acción gubernamental que busca crear una sociedad sometida enteramente a la dinámica competitiva [...] Para ello es preciso construir una trama social en la que todas sus unidades básicas (la familia, las instituciones de la sociedad civil, el Estado, los individuos) adquieran la 'forma empresa"' (Castro Gómez, 2010: p. 193).

Ya en 1979, el propio Foucault decía que "[...] la sociedad regulada según el mercado en la que piensan los neoliberales es una sociedad en la cual el principio regulador no debe ser tanto el intercambio de mercancías como los mecanismos de competencia... [con] la mayor superficie y espesor posibles [...] una sociedad de empresa [...]" (Foucault, 2007: p. 182). El neoliberalismo como racionalidad, o como tecnología de gobierno, supone expandir la forma del mercado, su lógica, a todos los ámbitos de la vida social. Tal forma de la competencia bajo las reglas del mercado no es natural sino que conlleva a la reforma artificial de las relaciones entre los individuos para convertirlos en sujetos competitivos, en empresarios de sí mismos. En palabras de Larner,

La concepción de una comunidad nacional de ciudadanos, conformada por hombres que aportan y mujeres que trabajan en la casa, ha sido usurpada por una nueva comprensión en que no sólo las firmas deben ser empresariales e innovadoras, sino también los sujetos políticos. Las estrategias neoliberales de dominio, encontradas en diversos ámbitos incluyendo lugares de trabajo, instituciones educacionales y agencias de salud y bienestar, animan a la gente a verse como sujetos activos e individualizados responsables por mejorar su propio bienestar [...] (Larner, 2000: p. 13. Traducción propia).

\section{Los procesos de identificación: entre gubernamentalidad y discurso}

Como vemos, la racionalidad neoliberal supone un reordenamiento de prácticas de gobierno al proveer ciertas reglas para posibilitar su articulación para que la estatalidad se delinee tras una "forma empresa" que se pretende imponer en todos los espacios posibles. Deteniéndonos en estas categorías, las prácticas se organizan en una "gramática que acompaña a las prácticas mismas y que se

10 En este punto consideramos que la noción de discurso y de lógica pueden volverse análogas bajo la común referencia a la categoría wittgensteiniana de "gramática", tal como la usa Laclau, esto es, "un refinado sistema de objetos, como una 'gramática' o grupo de reglas que hace que algunas combinaciones y sustituciones resulten posibles y excluye otras. Es lo que en nuestro trabajo hemos llamado 'discurso', que en un sentido amplio coincide con lo que la teoría lacaniana se llama 'simbólico”' (Laclau, 2004: p. 84). 
transforma con el tiempo. [...] esas gramáticas son un a priori histórico; son como el agua en la que nadan los peces: no las vemos pero siempre están allí, pues sin ellas no podríamos hablar ni actuar" (Castro Gómez, 2010: p. 30).

Ahora bien, con la definición del neoliberalismo como una racionalidad se vuelve posible un ejercicio de articulación epistemológica con el lenguaje de la TPD. Si bien las prácticas las regula una racionalidad, no se debe dar por supuesto que las primeras estén por completo subsumidas en la última. Es decir, según los presupuestos onto-epistémicos de la TPD, dicha gramática no posee un mecanismo de funcionamiento inmanente, sino que se encarna en procesos de identificación política con los que los sujetos definen parámetros legítimos de acción. ${ }^{11}$ Como afirma Laclau:

si lo simbólico fuera todo lo que hay en la vida social, las lógicas sociales y las prácticas sociales coincidirían con exactitud. Pero sabemos que en las prácticas sociales hay más que la puesta en acto de lo simbólico a través de performances institucionalizadas [...] Allí es donde reside, en nuestro análisis, el momento del antagonismo, el que $[\ldots]$ no es [...] sino el límite que la objetividad encuentra para constituirse (Laclau, 2004: p. 83).

Aquí adquiere preeminencia la presunción ontológica en la base de la TPD $y$, en general, en todo el postestructuralismo, sobre una falla constitutiva en lo social. Una ontología discursiva implica que la realidad social se estructura como conjunto relacional de diferencias. Una de estas ocupa un sitio ambiguo dentro de la estructura discursiva, el lugar de su límite. Por eso se encuentra fuera de esa articulación, pero es, al mismo tiempo, interior, ya que si no fuera así sería parte de otro conjunto relacional, el que se constituye entre el discurso primero y su diferencia habilitante. Pensada en la obra de Laclau y Mouffe de diversas maneras, esa diferencia se define como un antagonismo, como el producto de una exclusión frente a la que todos los elementos se equivalen. Si bien impide suturar absolutamente el conjunto relacional, lo vuelve posible de modo precario, es decir, "el límite de lo social debe darse en el interior mismo de lo social como algo que lo subvierte, es decir, como algo que destruye su aspiración a constituir una presencia plena” (Laclau \& Mouffe, 2005: p. 170). Yendo un poco más allá,

11 Así se toma distancia de los estudios sobre la gubernamentalidad neoliberal enfocados en el estudio de la biopolítica y el neoliberalismo sin preguntarse por la constitución de los actores que encarnan y consolidan dicha gubernamentalidad. Bajo la misma crítica, Larner considera que "es obvio que sin un análisis de las 'desordenadas actualidades' de los proyectos neoliberales particulares, los análisis al interior de este marco analítico [el de la gubernamentalidad] corren el riesgo precisamente del problema que desean evitar, el de producir explicaciones generalizadas de épocas históricas” (Larner, 2000: p. 14. Traducción propia). 
el antagonismo no puede ser aprehendido como tal, "sino sólo puesto de manifiesto bajo la forma de una interrupción o quiebre del proceso de significación" (Marchart, 2008: p. 187), que se entiende como dislocación.

$\mathrm{Al}$ estar entonces constitutivamente descentrado, todo discurso requiere de prácticas performativas para su "completamiento", haciendo posible ese "conjunto rarificado de objetos", como define Laclau a las lógicas sociales. Allí, "el espacio de este movimiento tropológico que subvierte el orden simbólico es el lugar de emergencia del sujeto" (Laclau, 2004: p. 86).

Es así que asumir el neoliberalismo como gubernamentalidad centrada en una lógica empresarial en todos los ámbitos sociales conduce a la pregunta por cómo se instanció el neoliberalismo en actores e institucionalidades puntuales. Esto implica correrse de un modelo de adaptación lineal de los actores a un curso histórico ya dado, para observar las encarnaciones particulares de una lógica que, como todo orden simbólico, encuentra una falla constitutiva en su centro. Foucault identificó una gubernamentalidad neoliberal a partir de un ejercicio genealógico de lectura de algunos autores de dicha corriente de la teoría económica (Foucault, 2007, 2008). Así, dispuso una serie de categorías y avances analíticos pertinentes para interrogarse por los procesos de identificación que son a la vez causa y efecto de la constitución de dicha racionalidad de gobierno. De esa manera, la definición foucaultiana de una racionalidad de gobierno neoliberal abre un espacio analítico para investigar los procesos políticos específicos a los que dio lugar, lo cual nos impulsa a subrayar las dinámicas discursivas de identificación, articulación y sobredeterminación con las que se promueve la expansión de una lógica de competencia de mercado a diversas interacciones sociales.

Existe un vínculo claro entonces entre los presupuestos onto-epistémicos, las caracterizaciones del neoliberalismo y los interrogantes planteados sobre los actores políticos bajo este "signo", durante la constitución del problema de investigación. Al comprender al neoliberalismo como un discurso político, el centro de atención pasa de un conjunto limitado de medidas económicas a nivel nacional hacia las relaciones de sentido, conflictivo y contingente, a través de las cuales diversos actores legitiman transformaciones estatales, estrategias partidarias, políticas sociales, entre otras, que expanden la forma-empresa hacia cualquier ámbito social.

Lo anterior conlleva mirar a los actores y contexto de un modo específico. Los primeros dejan de ser considerados como unidades autocentradas dirigidas por individuos que entablan relaciones exteriores de adaptación o reacción al contexto epocal en que se despliegan, decidiendo en función de cálculos exclusivamente racionales. La atención analítica se centra entonces en los procesos de identificación y en las trayectorias identitarias, por las que ciertos cursos de 
acción se vuelven verosímiles, legítimos o apropiados. Todo esto subraya la historicidad constitutiva de los actores políticos, en la cual la identidad de estos emerge precariamente en sucesivos intentos de identificación con discursos que pugnan por dotar de sentido a la realidad social, la que también se encuentra, así, constitutivamente dislocada. Prestar atención analítica a los devenires históricos y siempre desplazados de los actores políticos implica que no es posible a priori el estudio de sus definiciones en momentos puntuales de la historia, como si del mismo actor se tratase en reacciones ante cambios pretendidamente objetivos del contexto. Antes que en esas instancias precisas en el tiempo, los desplazamientos y parciales transformaciones en las trayectorias identitarias de los actores políticos se constituyen en el escenario en el cual el discurso neoliberal se instancia, y se vuelve disponible y creíble.

En efecto, entre el contexto y el actor se traza así un vínculo complejo que rechaza la mera exterioridad que presupone una racionalidad instrumental, para dar cuenta de los procesos de identificación por los que ese mismo contexto adquiere determinado contorno. El actor se articula en un horizonte de sentido relativamente estructurado. Este es el resultado contingente y parcialmente sedimentado de disputas, antes que el despliegue de una racionalidad inmanente o el reflejo más o menos apropiado de una estructura que se transforma como el resultado de procesos económicos o culturales.

El "clima de época" neoliberal no implica así un mero "dato ambiental" frente al que los actores se adaptan o lo rechazan, sino que pervive y se trasmuta parcialmente a partir de esos conflictivos procesos de identificación mediante los cuales se observan sus efectos. Esto imposibilita equiparar exhaustivamente el neoliberalismo con algún actor político que agotaría su sentido, como hemos visto que la literatura ha hecho en el caso argentino con el menemismo. Lejos de eso, la perspectiva que presentamos aquí permite pensar el neoliberalismo como un horizonte de sentido, conflictiva y contingentemente articulado, que ha dado lugar a heterogéneas experiencias con distintos alcances espaciotemporales. De esa manera, por ejemplo, la diversa presencia y persistencia de proyectos políticos neoliberales a nivel subnacional puede ubicarse por fuera de los límites temporales con que la literatura de las ciencias sociales ha ubicado en general la experiencia neoliberal en la Argentina, esto es, entre 1989 y 2001.

\section{Algunas notas para concluir}

El neoliberalismo aparece como un horizonte de sentido de importancia central para el análisis sociopolítico contemporáneo. De allí que las preguntas de investigación que surgen en torno suyo se multipliquen en diversas dimensiones, 
deteniéndonos aquí en el interrogante por la constitución de actores políticos neoliberales en las últimas décadas. En este artículo hemos presentado la relación entre determinadas caracterizaciones del neoliberalismo y las posibles preguntas de investigación que se abren a partir de aquellas. Una definición de este proceso como conjunto relativamente coherente de políticas económicas a nivel nacional, resultado del desarrollo de teorías económicas y de procesos estructurales en las últimas décadas del siglo $\mathrm{xx}$, da pie a dos tipos de pesquisas sobre los actores políticos constituidos bajo su influencia en la Argentina, intentando responder a la pregunta por la amplia aceptación a medidas de ajuste y desregulación a sectores de la población a la que perjudicaban. Una de ellas considera al pragmatismo y la capacidad de cálculo instrumental tanto de élites dirigenciales como de votantes, militantes y afiliados, además de tener en cuenta las características organizacionales de los partidos políticos que fueron protagonistas de la introducción de dichas medidas a nivel nacional. La otra hace hincapié en la discursividad puesta en juego por estos actores nacionales, centrándose en el menemismo, las asociaciones empresariales, académicas y sindicales, además del resto de las fuerzas políticas, para volver aceptable estas políticas, dando cuenta del carácter conflictivo y particular que acompañó su implementación.

Frente a estas líneas de investigación, centradas en actores políticos nacionales, hemos propuesto una caracterización novedosa del neoliberalismo para habilitar la pregunta por los actores neoliberales más acá del nivel nacional, e incluso más acá del conjunto de instituciones típicas del Estado de derecho, como los partidos políticos. El neoliberalismo se plantea entonces como una tecnología de gobierno, y por ende como parte integral de una racionalidad gubernamental centrada en el atravesamiento de la sociedad de una "forma empresa", que se expande o contrae mediante una dinámica discursiva. Así, esta caracterización del neoliberalismo no se agota en un contenido óntico determinado, más bien, abre el espacio para problematizar los procesos de identificación política por los que esa racionalidad, a la manera de un discurso político, se expande o contrae, se densifica o vuelve porosa, encarnándose de modo contingente y conflictivo en prácticas y sujetos particulares, que hablan así en nombre de una universalidad elusiva, la de la ya mentada "forma empresa" como criterio válido de organización social.

Se vuelve posible entonces un espacio de preguntas sobre los actores sociopolíticos que han encarnado la racionalidad neoliberal más allá de las derivas que se registraran en el Estado, o el conjunto de instituciones a él vinculadas, en el orden nacional. Esto implica, por último, dar pie a una perspectiva analítica relativamente novedosa para estudiar las continuidades, discontinuidades y modulaciones de los diversos discursos políticos en el escenario político argentino contemporáneo. 


\section{Referencias}

Aboy Carlés, G. (2001). Las dos fronteras de la democracia argentina. Buenos Aires: Homo Sapiens.

Anderson, P. (2003). Neoliberalismo: un balance provisorio. En La trama del neoliberalismo. Mercado, crisis y exclusión social (pp. 11-18). Buenos Aires: Consejo Latinoamericano de Ciencias Sociales.

Barros, S. (2002). Orden, democracia y estabilidad. Córdoba: Alción Editora.

Beltrán, G. (2008). Los intelectuales liberales: poder tradicional y poder pragmático en la Argentina reciente. Buenos Aires: Eudeba.

Borón, A. (1995). El experimento neoliberal de Carlos Saúl Menem. En Borón, A., Portantiero, J. C., Sidicaro, R. \& Mora y Araujo, M. Peronismo y menemismo: avatares del populismo en la Argentina (pp. 13-46). Buenos Aires: Ediciones El Cielo por Asalto.

Camou, A. (1998). Saber técnico y política en los orígenes del menemismo. Perfiles Latinoamericanos, 24(12), 85-107.

Canelo, P. (2001). ¿Dónde está el enemigo?: la rearticulación menemista de los clivajes políticos y la disolución del antagonismo social. Argentina, 1989-1995. Documento de trabajo. Buenos Aires: Consejo Latinoamericano de Ciencias Sociales.

Castro Gómez, S. (2010). Historia de la gubernamentalidad. Razón de Estado, liberalismo y neoliberalismo en Michel Foucault. Bogotá: Siglo del Hombre Editores.

Closa, G. (2010). Las transformaciones en el peronismo de Córdoba. En Tcach, C. (Coord.). Córdoba bicentenaria. Claves de su historia contemporánea (pp. 493-516). Córdoba: Centro de Estudios Avanzados.

Erbetta, C. (2011). La reconversión del estado durante la primera gobernación de Duhalde en la provincia de Buenos Aires. Trabajo y Sociedad, 16(xv), 287-298.

Foucault, M. (2007). Nacimiento de la biopolítica. Buenos Aires: Fondo de Cultura Económica.

Foucault, M. (2006). Seguridad, territorio y población. Buenos Aires: Fondo de Cultura Económica.

Gago, V. (2014). La razón neoliberal. Economias barrocas y pragmática popular. Buenos Aires: Tinta y Limón.

Gambina, J. (2001). Estabilización y reforma estructural en Argentina (1989-1999). En Sader, E. (Comp.). El ajuste estructural en América Latina (pp. 187-229). Buenos Aires: Clacso. 
Hall, S. (1988). The Toad in the Garden: Thatcherism among the Theorists. En Nelson, C. \& Grossberg, L. (Redactores). Marxism and the Interpretation of Culture (pp. 35-74). Urbana: University of Illinois Press.

Kant, I. (2010 [1793]). Teoría y praxis. Buenos Aires: Prometeo.

Laclau, E. (2014). Los fundamentos retóricos de la sociedad. Buenos Aires: Fondo de Cultura Económica.

Laclau, E. \& Mouffe, C. (2005). Hegemonía y estrategia socialista. Hacia una radicalización de la democracia. Buenos Aires: Fondo de Cultura Económica.

Laclau, E. (2004). Identidad y hegemonía: el rol de la universalidad en la constitución de identidades políticas. En Butler, J., Laclau, E. \& Žižek, S. Contingencia, hegemonía y universalidad. Diálogos contemporáneos desde la izquierda (pp. 49-93). Buenos Aires: Fondo de Cultura Económica.

Larner, W. (2000). Neo-liberalism: Policy, Ideology, Governmentality. Studies in Political Economy, (63), 5-25.

Lemke, T. (2006). Marx sin comillas: Foucault, la gubernamentalidad y la crítica del neoliberalismo. En Lemke, T., Legrand, S., Le Blanc, G., Montag, W., Jessop, B. \& Giacomelli, M. E. Marx y Foucault (pp. 5-20). Buenos Aires: Nueva Visión.

Levitsky, S. (2005). La transformación del justicialismo. Del partido sindical al partido clientelista, 1983-1999. Buenos Aires: Siglo XXI.

Levitsky, S. (2001). Una "des-organización organizada”: organización informal y persistencia de estructuras partidarias locales en el peronismo argentino. Revista de Ciencias Sociales, 12, $7-62$.

Manzo, A. (2011, julio-diciembre). La penetración del neoliberalismo en los ámbitos subnacionales. El caso Córdoba: análisis de las leyes provinciales del Estado nuevo y el Pacto fiscal. Civilizar, Ciencias Sociales y Humanas, 11(21), 15-32.

Marchart, O. (2008). El pensamiento político posfundacional. La diferencia politica en Nancy, Lefort, Badiou y Laclau. Buenos Aires: Fondo de Cultura Económica.

Morresi, S. (2008). La nueva derecha argentina. Buenos Aires: UNGS.

Muñoz, M. A. (2010). Sísifo en Argentina. Orden, conflicto y sujetos políticos. Villa María: Eduvim. 
Portantiero, J. C. (1995). Menemismo y peronismo: continuidad y ruptura. En Peronismo y menemismo: avatares del populismo en la Argentina (pp. 101-118). Buenos Aires: Ediciones El Cielo por Asalto.

Pucciarelli, A. (Coord.) (2011). Los años de Menem. La construcción del orden neoliberal. Buenos Aires: Siglo Veintiuno Editores.

Pucciarelli, A. \& Castellani, A. (Comps.) (2014). Los años de la Alianza. La crisis del orden neoliberal. Buenos Aires: Siglo Veintiuno Editores.

Reynares, J. M. (2014). El peronismo cordobés en los noventa. Algunas notas sobre identificación neoliberal y práctica partidaria. Revista Enfoques, 12(21), 111-130.

Reynares, J. M. (2012a). La identidad politica de la Renovación. El peronismo cordobés en la transición democrática. Villa María: Eduvim.

Reynares, J. M. (2012b). La política en boca de expertos: tecnocracia y consolidación neoliberal. En Bonetto, M. S. \& Martínez, F. (Comps.). Política y desborde. Más allá de una democracia liberal (pp. 75-108). Villa María: Eduvim.

Rose, N. (2012). Politicas de la vida. Biomedicina, poder y subjetividad en el siglo XXI. La Plata, Argentina: Unipe Editorial Universitaria.

Rose, N., O’Malley, P. \& Valverde, M. (2012). Gubernamentalidad. Astrolabio Nueva Época, 8, 113-152.

Rossi, M. A. \& Blengino, L. F. (2011). La lógica del neoliberalismo a partir de la interlocución de Immanuel Kant y la impronta de Michel Foucault. En Rossi, M. A. \& López, A. (Comps.). Crisis y metamorfosis del Estado argentino: el paradigma neoliberal en los noventa (pp. 19-46). Buenos Aires: Ediciones Luxemburg.

Sidicaro, R. (1995). Poder político, liberalismo económico y sectores populares. En Borón, A., Portantiero, J. C., Sidicaro, R. \& Mora y Araujo, M. Peronismo y menemismo: avatares del populismo en la Argentina (pp. 119-156). Buenos Aires: Ediciones El Cielo por Asalto.

Recibido el 30 de septiembre de 2015. Aceptado el 24 de noviembre de 2016. 